\title{
Brain-Derived Neurotrophic Factor Acutely Inhibits AMPA-Mediated Currents in Developing Sensory Relay Neurons
}

\author{
Agnieszka Balkowiec, Diana L. Kunze, and David M. Katz \\ Department of Neurosciences, Case Western Reserve University School of Medicine, Cleveland, Ohio 44106
}

Brain-derived neurotrophic factor (BDNF) is expressed by many primary sensory neurons that no longer require neurotrophins for survival, indicating that BDNF may be used as a signaling molecule by the afferents themselves. Because many primary afferents also express glutamate, we investigated the possibility that BDNF modulates glutamatergic AMPA responses of newborn second-order sensory relay neurons. Perforated-patch, voltage-clamp recordings were made from dissociated neurons of the brainstem nucleus tractus solitarius (nTS), a region that receives massive primary afferent input from BDNF-containing neurons in the nodose and petrosal cranial sensory ganglia. Electrophysiological analysis was combined in some experiments with anterograde labeling of primary afferent terminals to specifically analyze responses of identified second-order neurons. Our data demonstrate that BDNF strongly inhibits AMPAmediated currents in a large subset of nTS cells. Specifically,

Brain-derived neurotrophic factor (BDNF) acts as a targetderived survival factor for subsets of developing primary sensory neurons (Hallbook and Fritzsch, 1997; Brady et al., 1999; Fritzsch et al., 1999). In addition, however, many primary sensory neurons themselves express and can release BDNF, even when they are no longer dependent on BDNF for survival (Schecterson and Bothwell, 1992; Wetmore and Olson, 1995; Apfel et al., 1996; Zhou et al., 1998; Brady et al., 1999). This finding raises the possibility that BDNF plays additional roles in sensory pathway development or function, including a role in afferent synaptic transmission. In support of this possibility, a subset of dorsal root ganglion (DRG) sensory neurons transports BDNF in their projections to the spinal cord (Zhou and Rush, 1996; Tonra, 1999), and BDNF is localized to dense-core vesicles within DRG central axon terminals (Michael et al., 1997). In addition, Kerr et al. (1999) demonstrated that BDNF can potentiate nociceptive spinal reflexes, most likely by enhancing NMDA receptor-mediated responses. Moreover, studies in other neural systems have shown that BDNF can acutely regulate synaptic transmission and neuronal activity. For example, BDNF application increases the frequency of EPSCs at the neuromuscular junction (Lohof et al., 1993) and in cultured hippocampal neurons (Lessmann et al., 1994; Levine et al., 1995, 1996) as well as excitability of cortical (Rutherford et al.,

\footnotetext{
Received Oct. 14, 1999; revised Dec. 6, 1999; accepted Dec. 17, 1999.

This work was supported by Public Health Service grants (National Heart, Lung, and Blood Institute) to D.M.K. and D.L.K. We gratefully acknowledge the helpful comments of Drs. Stephen Jones and Ben Strowbridge.

Correspondence should be addressed to Dr. David M. Katz, Department of Neurosciences, Case Western Reserve University School of Medicine, 10900 Euclid Avenue, Cleveland, OH 44106. E-mail: dmk4@po.cwru.edu.

Copyright (C) 2000 Society for Neuroscience $0270-6474 / 00 / 201904-08 \$ 15.00 / 0$
}

AMPA responses were either completely abolished or markedly inhibited by BDNF in $73 \%$ of postnatal day (P0) cells and in $82 \%$ of identified P5 second-order sensory relay neurons. This effect of BDNF is mimicked by NT-4, but not NGF, and blocked by the Trk tyrosine kinase inhibitor K252a, consistent with a requirement for TrkB receptor activation. Moreover, analysis of TrkB expression in culture revealed a close correlation between the percentage of nTS neurons in which BDNF inhibits AMPA currents and the percentage of neurons that exhibit TrkB immunoreactivity. These data document a previously undefined mechanism of acute modulation of AMPA responses by BDNF and indicate that BDNF may regulate glutamatergic transmission at primary afferent synapses.

Key words: AMPA; BDNF; glutamate; nucleus tractus solitarius; sensory neurons; synaptic plasticity; synaptic transmission

1997), hippocampal-entorhinal (Scharfman, 1997), and spinal motoneurons (Gonzalez and Collins, 1997). In addition, BDNF induces a long-lasting increase in synaptic transmission in hippocampal slices from adult rat (Kang and Schuman, 1995a) and facilitates induction of hippocampal long-term potentiation (LTP; Figurov et al., 1996). BDNF knock-out mice have a deficit in basal synaptic transmission, as well as LTP (Korte et al., 1995), both of which can be reversed by exogenous BDNF (Patterson et al., 1996). These data, coupled with findings that BDNF synthesis and release are activity-dependent (Castrén et al., 1992; Bozzi et al., 1995; Thoenen, 1995; McAllister et al., 1997), support the view that BDNF can act acutely as a synaptic neuromodulator.

BDNF-containing primary sensory neurons are most abundant in cranial sensory ganglia, including the nodose-petrosal ganglion (NPG) of the vagal and glossopharyngeal nerves (Brady et al., 1999). These neurons convey visceral sensory information and project centrally to the brainstem nucleus tractus solitarius (nTS), which expresses high levels of the BDNF receptor TrkB (Yan et al., 1997). The major transmitter of NPG sensory neurons is L-glutamate (Andresen and Yang, 1990; Ambalavanar et al., 1998; Smith et al., 1998; Zhang and Mifflin, 1998; Botsford et al., 1999), raising the possibility that BDNF modulates glutamatergic transmission between primary afferents and second-order neurons in nTS. The present study was designed to test this possibility using voltage-clamp recording from identified second-order nTS neurons. We focused in particular on interactions between BDNF and the AMPA subtype of glutamate receptors, which mediates fast excitatory neurotransmission (Ozawa et al., 1998). Our data demonstrate that BDNF, acting through the TrkB receptor, strongly inhibits AMPA responses in second-order sensory relay neurons. 


\section{MATERIALS AND METHODS}

Cell preparation. Newborn rats (Sprague Dawley strain; Zivic-Miller, Zelienople, PA) were killed by exposure to carbon dioxide and decapitated. Blocks of tissue were isolated from the nucleus tractus solitarius (nTS) at the level of the obex of the fourth ventricle. The tissue was subdivided into several smaller pieces and dissociated by gentle trituration through glass Pasteur pipettes of successively smaller tip diameters. The cells were plated on poly-D-lysine-treated coverslips and grown for $24 \mathrm{hr}$ in DMEM-F12 medium (Life Technologies, Gaithersburg, MD) with $10 \%$ fetal bovine serum (HyClone, Logan, UT). The analyzed cells were selected based on morphological criteria characteristic of secondorder relay neurons, i.e., round or oval bipolar cells, $10-20 \mu \mathrm{m}$ in diameter, with thin processes (Fig. 4B, large arrow; see also Mendelowitz et al., 1992).

Dye labeling. We used a modification of the technique previously described by Mendelowitz and colleagues (1992) to label presynaptic boutons on second-order nTS neurons. Briefly, newborn [postnatal day 0 (P0)] rats were anesthetized by hypothermia combined with local application of Lidocaine $\mathrm{HCl}$ (Abbott Laboratories). Both vagal nerves were exposed in the neck by a ventral midline excision and isolated from surrounding tissues with Parafilm "M" (Fisher Scientific, Houston, TX). Small crystals of the anterograde tracer 4-(4-(didecylamino)styryl)- $N$ methyl-pyridinium iodide (DiA) (4-Di-10-ASP; Molecular Probes, Eugene, OR) were placed on the isolated intact nerves at the level of the carotid bifurcation and caudal to the nodose ganglion. To prevent dye leakage to surrounding tissues, the region was isolated with a fast hardening silicone elastomer (Kwik-Sil; World Precision Instruments). The animals were then sutured and allowed to recover for 5-9 d. All experiments were performed in compliance with the guidelines of the Case Western Reserve University Institutional Animal Care and Use Committee. nTS neurons were prepared essentially as described above for P0 animals, except that the cells were dissociated and plated in the presence of reduced calcium (0.2 mM; Mendelowitz et al., 1992). Recordings from labeled $\mathrm{P} 5 / \mathrm{P} 9$ neurons began $6-8 \mathrm{hr}$ after dissociation, and the second-order sensory neurons were identified by the presence of fluorescing boutons attached to the soma. Only brief exposure to UV light, not exceeding 10-20 sec, was used to identify labeled neurons.

Electrophysiology. The neurons were studied using the amphotericin perforated-patch recording technique in voltage-clamp mode (Hamill et al., 1981; Rae et al., 1991). The extracellular solution contained (in mM): $\mathrm{NaCl} 137, \mathrm{KCl} 5.4, \mathrm{MgCl}_{2} 1, \mathrm{CaCl}_{2}$ 2, glucose 10, and HEPES 10. In experiments in which voltage-activated calcium channels were blocked, the $\mathrm{CaCl}_{2}$ concentration was decreased to $0.02 \mathrm{mM}$, and $0.5 \mathrm{~mm}$ cadmium succinate was added. The pipette solution contained (in $\mathrm{mM}$ ): $\mathrm{NaCl} 10$, $\mathrm{KCl} 50, \mathrm{~K}_{2} \mathrm{SO}_{4} 50, \mathrm{MgCl}_{2}$ 5, and HEPES 10. Recordings were performed in room temperature with patch pipettes pulled from 7052 glass and fire-polished to a final resistance of 3-5 M , using an Axopatch-200A (Axon Instruments, Foster City, CA) patch-clamp amplifier. The membrane potential was held at $-60 \mathrm{mV}$. Signals were filtered at $2 \mathrm{kHz}$, digitized on-line at a sampling rate of $10 \mathrm{kHz}$, and stored for later computer analysis using pClamp version 5.7 software (Axon Instruments).

BDNF and NT-4 were generously provided by Regeneron Pharmaceuticals (Tarrytown, NY), and NGF was provided by Dr. Kenneth Neet (Chicago Medical School). All other reagents were purchased: AMPA (Sigma, St. Louis, MO), K252a and K252b (Calbiochem, La Jolla, CA). All drugs were diluted in the extracellular solution and applied to the cell using a multibarrel pipette and a rapid, gravity-driven perfusion system (a modification of the U-tube design; Murase et al., 1989). K252a and $\mathrm{K} 252 \mathrm{~b}$ were initially dissolved in DMSO at $2 \mathrm{~mm}$; the final concentration of DMSO in the working solutions, $0.01 \%$, has no effect on neuronal function (Kang and Schuman, 1995b).

TrkB immunocytochemistry. Cultures grown as described above for 24 or $72 \mathrm{hr}$, and tissue sections, were stained as previously described (Brady et al., 1999) using chicken polyclonal anti-TrkB (Promega, Madison, WI) and donkey anti-chicken biotinylated IgG (Accurate Chemicals, Westbury, NY). Control slides, in which primary antibody was omitted, were completely devoid of staining. Because the percentage of TrkB-positive neurons was not different in 24 and $72 \mathrm{hr}$ nTS cultures, the data were pooled.

Confocal microscopy. Images of labeled second-order nTS neurons were taken with a Zeiss LSM 410 confocal laser microscope (Zeiss, Göttingen, Germany), using an argon-krypton laser (excitation line 488) and a $100 \times$ Plan-Neofluar, numerical aperture 1.3, oil objective.

Statistical analysis. Data were analyzed by integrating, for each neuron, the AMPA-evoked current under control conditions and during drug application, using Clampfit version 6.0 software (Axon Instruments). Data are presented as mean \pm SEM and were analyzed by ANOVA for repeated measures followed by Duncan's multiple comparison procedure. $p<0.05$ was considered significant.

\section{RESULTS}

To assess the effects of BDNF on postsynaptic AMPA responses in dissociated nTS neurons, we recorded currents evoked by a 2 sec pulse application of AMPA $(150 \mu \mathrm{M})$, a selective agonist of the AMPA subtype of glutamatergic receptors, in the absence and presence of $50 \mathrm{ng} / \mathrm{ml} \mathrm{BDNF}$, using the perforated-patch technique (Materials and Methods). Studies were performed on 113 P0 neurons, selected on the basis of morphological criteria characteristic of second-order relay cells (Materials and Methods), and on 11 P5/P9 nTS neurons specifically identified as second-order relay neurons by dye labeling of presynaptic boutons (Materials and Methods). In both unlabeled and labeled cells, application of AMPA alone activated a rapidly decaying inward current followed by a prolonged component of lower amplitude (Fig. 1A). AMPA-evoked currents were completely blocked by CNQX $(20 \mu \mathrm{M}, n=12)$, a competitive antagonist of non-NMDA receptors.

The effects of BDNF were analyzed using an experimental paradigm in which, after two or three control applications of AMPA, $50 \mathrm{ng} / \mathrm{ml}$ BDNF was applied to the extracellular solution for $1 \mathrm{~min}$, followed by BDNF plus AMPA for $2 \mathrm{sec}$. The simultaneous application of AMPA and BDNF was repeated twice in $1 \mathrm{~min}$ intervals during which $50 \mathrm{ng} / \mathrm{ml} \mathrm{BDNF}$ was continuously present in the extracellular solution. Following the test applications of AMPA and BDNF, the extracellular solution containing BDNF was replaced with control solution, and 1 min later, AMPA was applied alone (recovery; Fig. $1 A$ ). The BDNF concentration of $50 \mathrm{ng} / \mathrm{ml}$ was chosen based on previous studies of acute BDNF effects on neuronal function in culture (Lessmann et al., 1994; Levine et al., 1995; Song et al., 1998).

In unlabeled, P0 nTS neurons, AMPA responses were either completely abolished (27 cells, 24\%) or inhibited (55 cells, 49\%) by BDNF. An AMPA response was considered inhibited by BDNF if, in the presence of BDNF, it fell below the distribution of control AMPA responses, i.e., it was $<75 \%$ of control current (see Fig. $1 B$ for details). The distribution analysis of BDNF effects on AMPA responses in the entire population of 113 P0 nTS neurons tested, expressed as a percent of control, revealed three subpopulations: (1) $0-5 \%$, corresponding to complete blockade of AMPA currents, (2) 5-75\%, corresponding to partial inhibition of AMPA responses, and (3) 75-125\%, representing a neuronal population not affected by BDNF and matching the distribution of control AMPA responses (Fig. 1B). This result suggests that there are three distinct subpopulations of nTS neurons with respect to the effects of BDNF on AMPA responses. However, because we were not able to identify any additional independent feature distinguishing the two subpopulations of cells in which AMPA responses were affected by BDNF, such as cell size or the magnitude of the control AMPA responses, these two groups were combined for further analysis.

In the subpopulation of P0 nTS neurons affected by BDNF, AMPA responses were inhibited on average by $67.9 \pm 5.5 \%(n=$ $82, p<0.001)$ during the first BDNF application. Two subsequent applications of AMPA in the presence of BDNF showed a similar degree of inhibition $(68.3 \pm 5.6 \%$ and $67.8 \pm 5.5 \%$, respectively; Fig. 2). This demonstrates that the maximum BDNF 


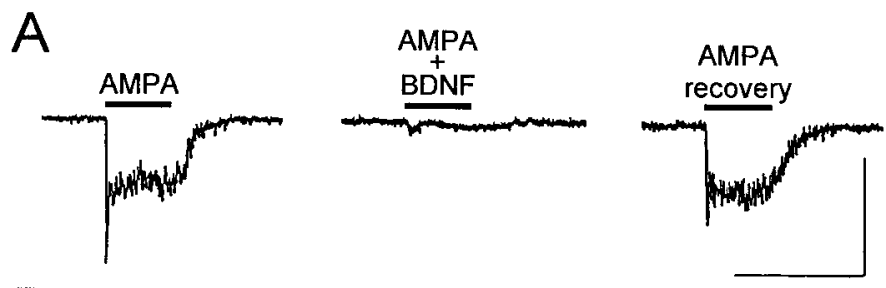

B
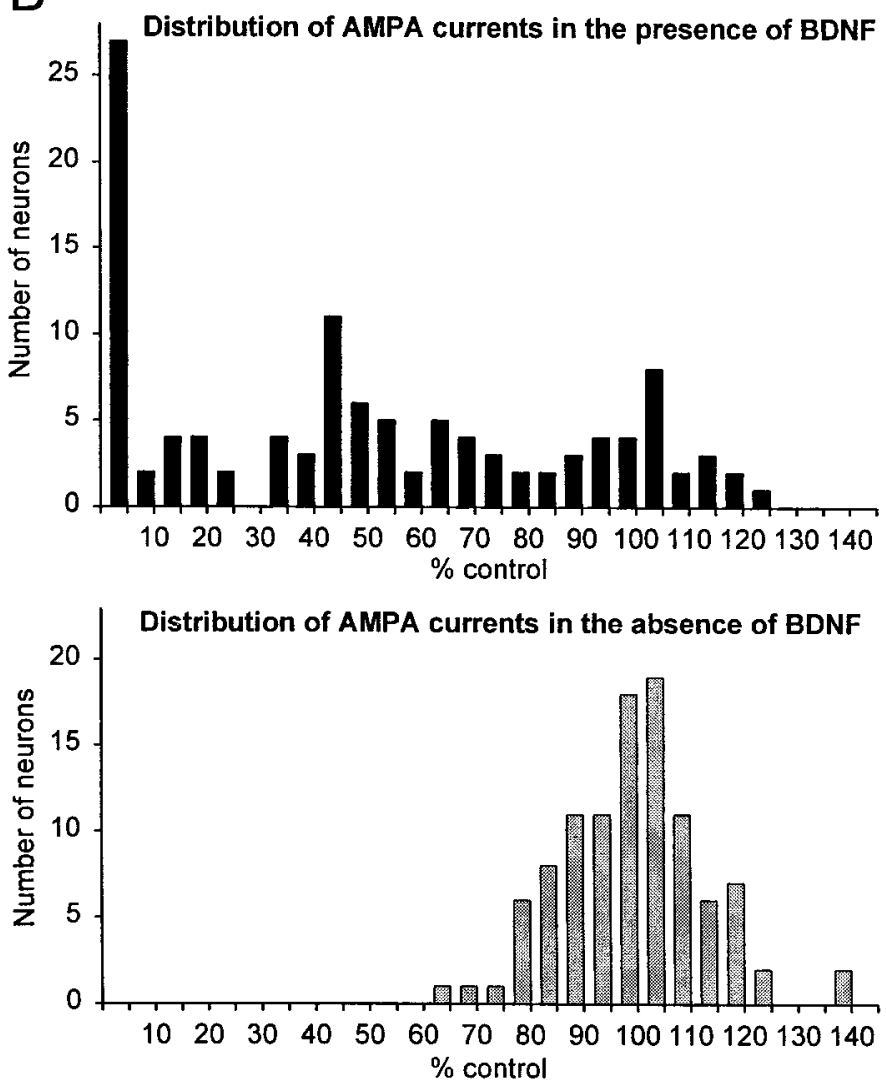

Figure 1. Effects of BDNF on AMPA currents in P0 nTS neurons. $A$, Sample recording of BDNF effect on AMPA currents in a P0 nTS neuron. The neuron was first superfused with control bath solution followed by a $2 \mathrm{sec}$ pulse of $150 \mu \mathrm{M}$ AMPA alone (horizontal bar; $A M P A$ ). The solution was then switched to one containing BDNF $(50 \mathrm{ng} / \mathrm{ml})$, and, 1 min later, $150 \mu \mathrm{M}$ AMPA plus $50 \mathrm{ng} / \mathrm{ml}$ BDNF was simultaneously applied for $2 \mathrm{sec}$ $(A M P A+B D N F)$. After 1 min rinse with control bath solution, the application of AMPA alone was repeated (AMPA recovery). Calibration: $4 \mathrm{sec}, 50 \mathrm{pA}$. B, The distribution of AMPA currents in the presence (top panel) and absence (bottom panel) of BDNF in the entire population of P0 nTS neurons tested. AMPA currents in the presence of BDNF are expressed as a percentage of control AMPA currents evoked by the application of AMPA alone before BDNF treatment. AMPA currents in the absence of BDNF represent currents evoked by a second control application of AMPA expressed as a percentage of the first control application. The distribution of control AMPA currents shows a variability of $25 \%$ in the control responses. Therefore, the effect of BDNF was considered significant when the AMPA current in the presence of BDNF was $<75 \%$ of the control AMPA current.

effect is already reached during the first minute of application and persists in the continued presence of BDNF.

To rule out the possibility that BDNF acts presynaptically, e.g., by stimulating release of an inhibitory transmitter from adherent synaptic boutons (Drewe et al., 1988), we tested the effect of blocking voltage-activated calcium channels $\left(0.5 \mathrm{mM} \mathrm{Cd}^{2+}, 0.02\right.$ $\mathrm{mm} \mathrm{Ca}^{2+}$ ) on BDNF inhibition of AMPA currents. In 7 of the 11

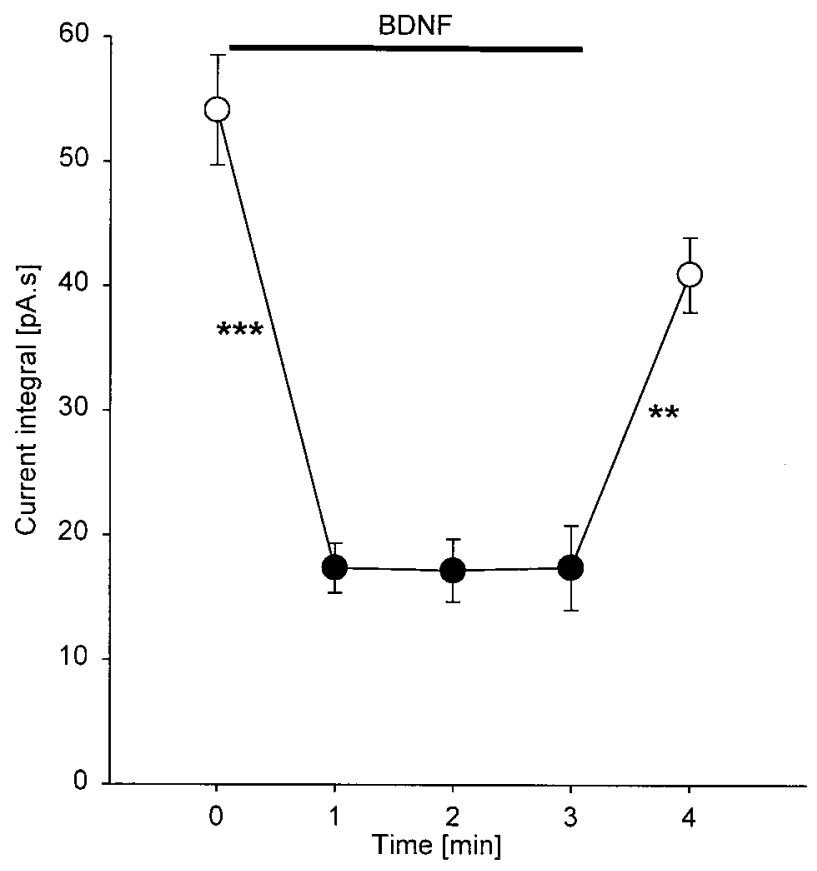

Figure 2. Comparison of the effects of three subsequent applications of AMPA + BDNF (closed circles) after control application of AMPA alone (open circle, time 0). Recovery from the BDNF effect was reached $1 \mathrm{~min}$ after BDNF was removed from the bath (open circle). $n=82 ;{ }^{* *} p<0.01$; *** $p<0.001$.

P0 nTS neurons tested, AMPA responses were either completely abolished $(n=3)$ or markedly inhibited $(49.9 \pm 13.16 \%$ of control, $n=4, p=0.019$ ) by BDNF, paralleling results obtained in normal calcium-containing medium. The persistence of BDNF inhibition of AMPA responses in the absence of calcium influx indicates a direct effect, not requiring calcium-mediated transmitter release from either presynaptic terminals or the nTS neurons themselves. In addition, application of BDNF alone was not accompanied by any significant or consistent change in the input resistance (mean percentage of baseline: $95.62 \pm 7.96, n=10$, $p>0.05$ ), indicating that the intrinsic membrane properties of the cells were not affected by BDNF.

To specifically identify second-order sensory relay neurons (defined as nTS cells that receive primary afferent input), primary afferents were prelabeled in newborn animals with the anterograde tracer DiA (Materials and Methods). Five to nine days later the nTS region was dissociated, and second-order sensory neurons were identified by the presence of fluorescent presynaptic boutons (Fig. $3 A$ ). In 9 of the 11 identified neurons tested, AMPA responses were either completely abolished (two neurons) or markedly inhibited (seven neurons) by BDNF. On average, there was $76.4 \pm 5.2 \%$ inhibition of AMPA currents by BDNF $(n=9, p<0.01$; Fig. $3 B$ ). The results obtained from identified second-order nTS neurons were virtually identical to those obtained in unlabeled P0 nTS cells (Fig. 3C), indicating that the population of $\mathrm{P} 0$ neurons tested was representative of the population of relay neurons. Therefore, unlabeled P0 cells were used for further analysis.

Immunocytochemical staining demonstrated that a subset of nTS neurons expresses the BDNF receptor TrkB in vivo (Fig. 4A) and in dissociate culture (Fig. $4 B$ ). To determine whether the percentage of TrkB-positive nTS neurons correlated with the percentage of neurons in which BDNF inhibited AMPA currents, 


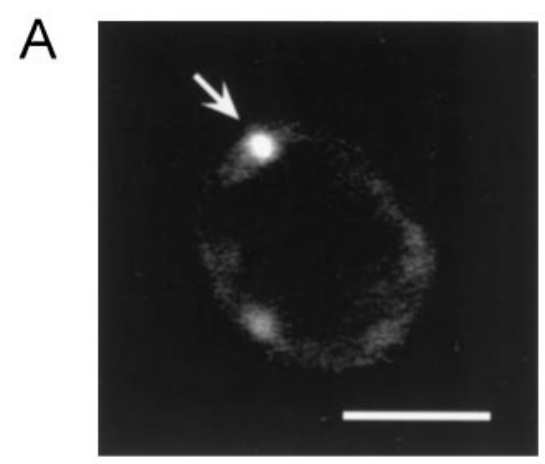

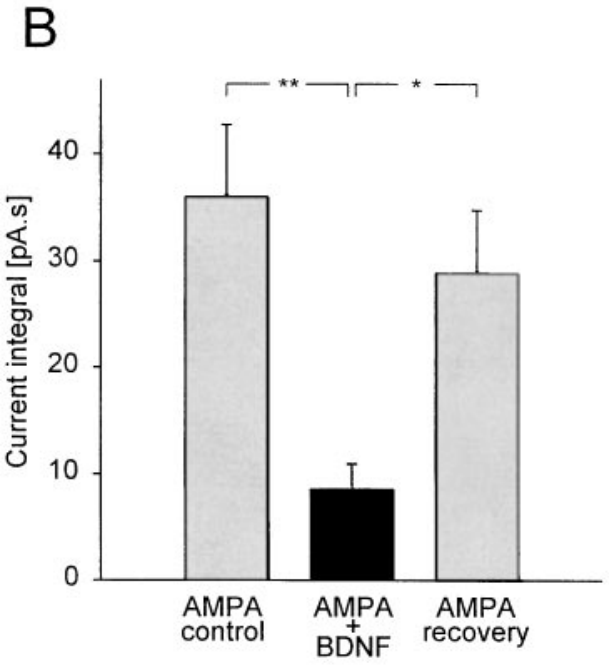

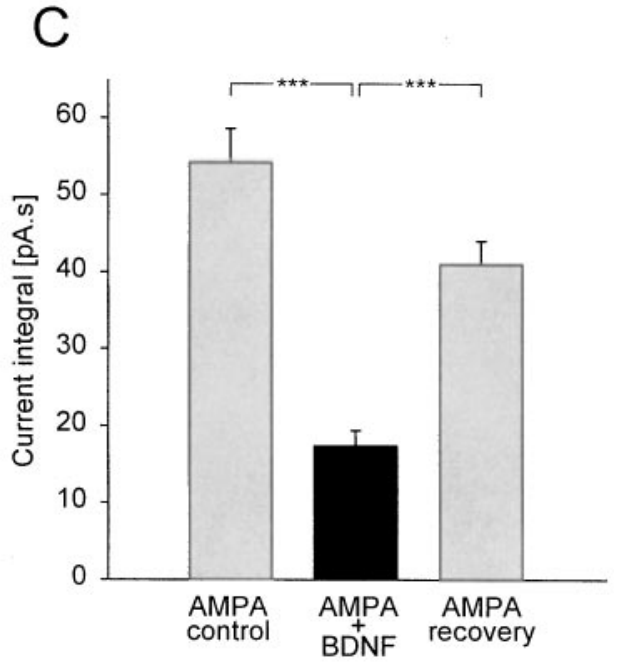

Figure 3. Effects of BDNF on AMPA currents in $\mathrm{P} 5 / \mathrm{P} 9$ identified second-order sensory neurons. $A$, Confocal image (a single optical section of $719 \mathrm{~nm}$ ) of a P9 nTS neuron showing an attached, DiA-filled, synaptic bouton (arrow), taken $6 \mathrm{hr}$ after dissociation. Scale bar, $5 \mu \mathrm{m}$. $B, C$, Mean integrated currents evoked by a control 2 sec application of AMPA alone (AMPA control), simultaneous application of AMPA and BDNF after 1 min BDNF pretreatment $(A M P A+B D N F)$, and after return to superfusion with control bath solution (AMPA recovery), recorded in $\mathrm{P} 5 / \mathrm{P} 9$ labeled nTS neurons $(B ; n=9)$, and compared to $\mathrm{P} 0$ neurons $(C ; n=82)$. ${ }^{*} p<0.05$; ${ }^{* *} p<0.01 ; * * * p<0.001$. detailed analysis of TrkB staining was performed on a population of cultured nTS neurons selected according to the same morphological criteria used in our electrophysiological studies. This analysis revealed that $83 \%$ (76 of 92) of P0 cells and 78\% (57 of 73) of P5 cells were TrkB-positive, findings that closely match the percentage of cells in which BDNF inhibited AMPA responses at both ages $(74 \%, \mathrm{P} 0 ; 82 \%, \mathrm{P} 5)$. Therefore, to directly examine the role of TrkB activation in BDNF inhibition of AMPA currents, we analyzed the effect of the Trk tyrosine kinase inhibitor K252a. Eight P0 nTS neurons in which AMPA responses were either abolished $(n=3)$ or partially blocked $(n=5)$ by BDNF were tested for the effects of K252a. Following control applications of AMPA and AMPA plus BDNF (as described above; Fig. 4C, control), the cells were superfused with $200 \mathrm{~nm} \mathrm{K252a}$ for 12-15 min, after which application of AMPA and AMPA plus BDNF was repeated as before (Fig. 4C, K252a). Following K252a treatment, BDNF had no effect on AMPA responses (Fig. 4D), consistent with the hypothesis that BDNF inhibition of AMPA currents requires Trk receptor tyrosine kinase activity. Because K252a inhibits Trk receptor tyrosine kinases preferentially, but not with absolute specificity, we also tested the effect of K252b, a structural analog of K252a that is characterized by a markedly lower potency for Trk receptor tyrosine kinase inhibition (Kang and Schuman, 1995b). We tested four cells in which BDNF completely abolished AMPA responses under control conditions. Using the same experimental protocol that was used for K252a, $200 \mathrm{~nm} \mathrm{~K} 252 \mathrm{~b}$ was ineffective at inhibiting the effect of BDNF on AMPA responses (Fig. 4E). To further define the specificity of BDNF action on AMPA responses, we also examined the effect of NT-4, the other known TrkB receptor ligand (Ip et al., 1992; Klein et al., 1992), as well as NGF, which acts through the TrkA receptor. In 22 nTS neurons in which BDNF inhibited AMPA responses, NT-4 $(50 \mathrm{ng} / \mathrm{ml})$ completely mimicked the effect of BDNF (Fig. $5 A$ ). In contrast, NGF $(50 \mathrm{ng} / \mathrm{ml})$ had no detectable effect on AMPA responses in 12 neurons in which BDNF either partially or completely inhibited AMPA currents (Fig. 5B). Together, these results strongly indicate that BDNF inhibition of AMPA responses is mediated through TrkB receptor activation.

\section{DISCUSSION}

The present study demonstrates that BDNF markedly inhibits AMPA receptor-mediated currents in a large subset of newborn nTS neurons, including identified second-order sensory relay cells. This effect of BDNF was mimicked by NT-4, but not NGF, and blocked by the Trk tyrosine kinase inhibitor K252a, consistent with a requirement for TrkB receptor activation.

Most studies on the acute neuromodulatory effects of neurotrophins at central synapses have focused on NMDA responses and demonstrated enhanced glutamatergic transmission in the presence of BDNF (Lessmann et al., 1994; Kang and Schuman, 1995a; Lessmann and Heumann, 1998; Levine et al., 1998). In contrast, our data indicate that AMPA responses are strongly inhibited by BDNF. Previous studies have hinted at an inhibitory action of BDNF on central neurons. Lessmann et al. (1994) reported a reversible inhibition of evoked synaptic currents in $15 \%$ of hippocampal cells after application of BDNF or NT-4. Similarly, BDNF and NT-4 depressed glutamatergic synaptic transmission in $10 \%$ of cultured hippocampal neurons (Lessmann and Heumann, 1998). Exogenous BDNF has also been shown to acutely suppress spontaneous synaptic activity in hippocampal cultures via non-NMDA receptors and to increase activity through NMDA receptors (Song et al., 1998). Thus, we consider 

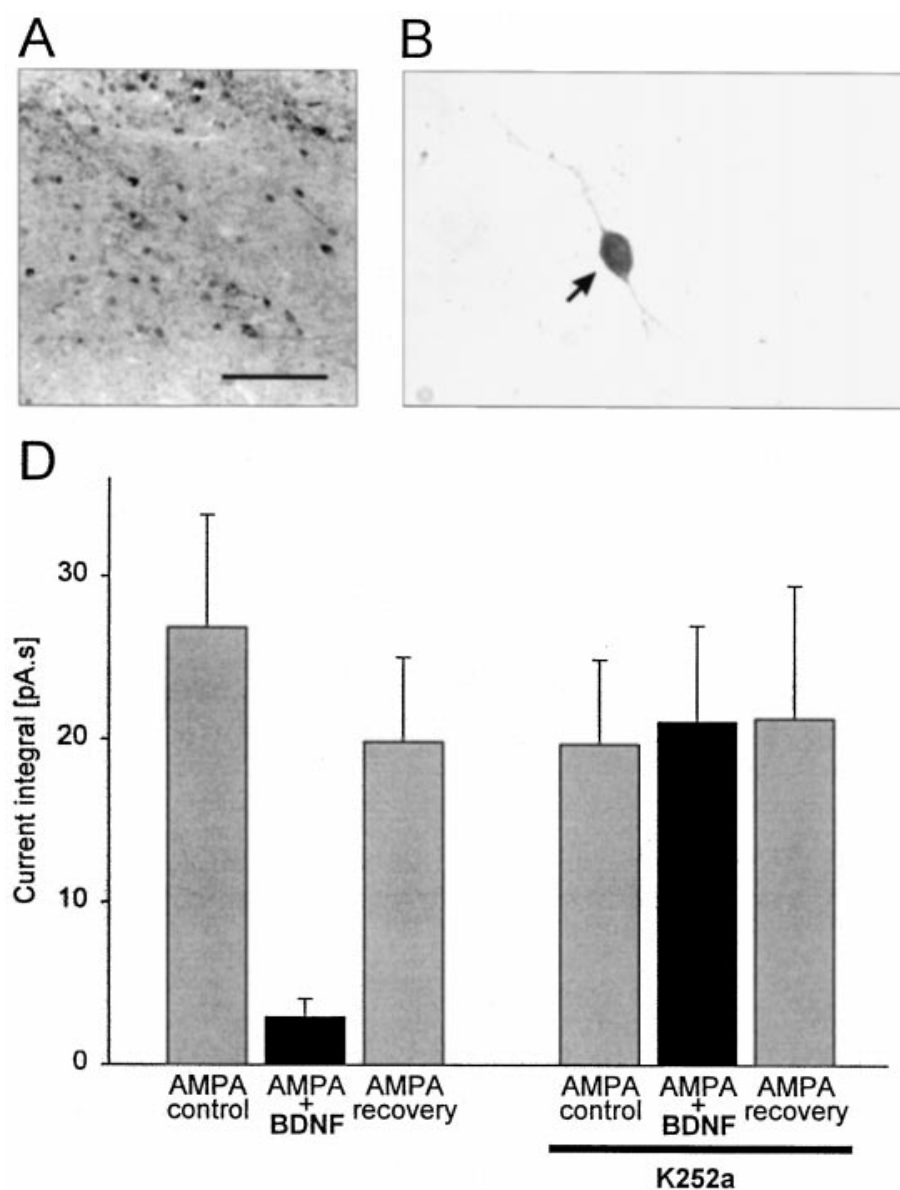
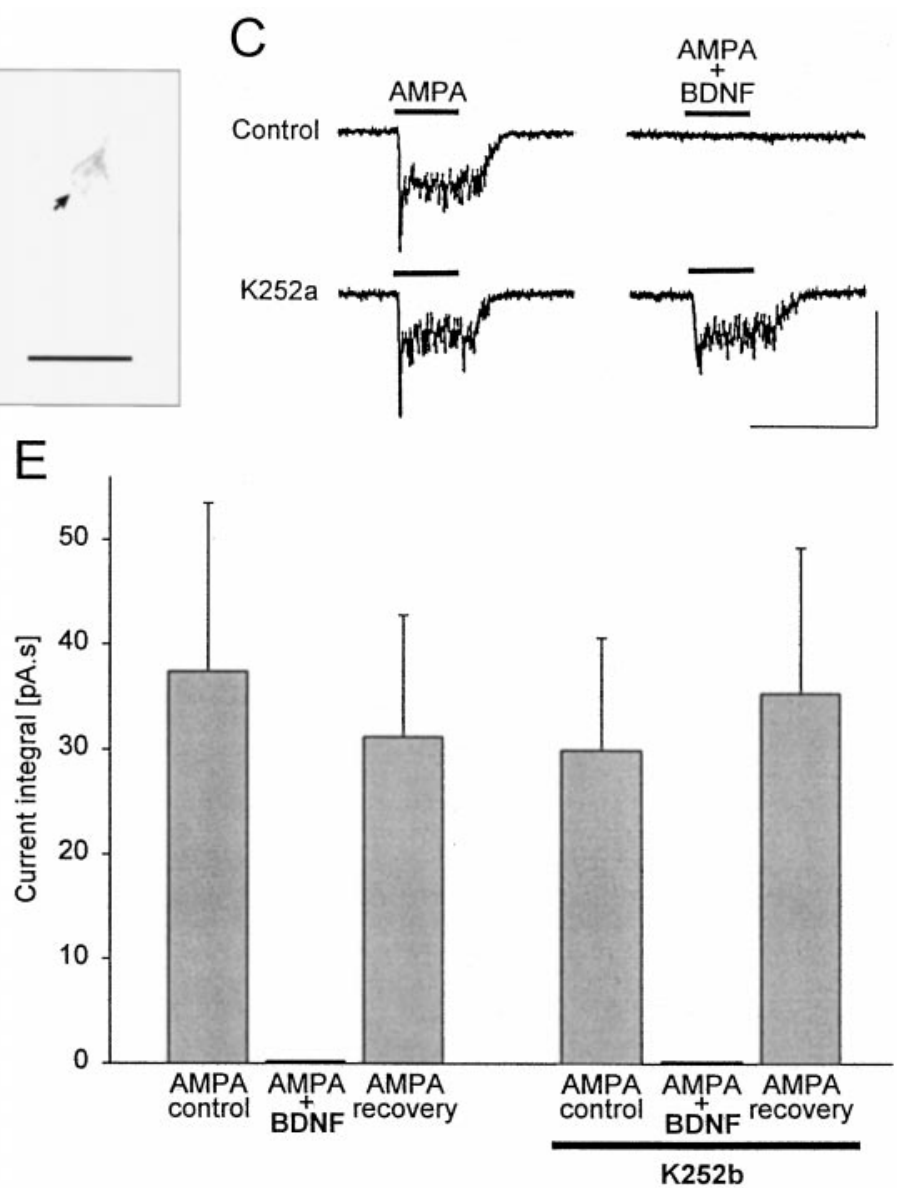

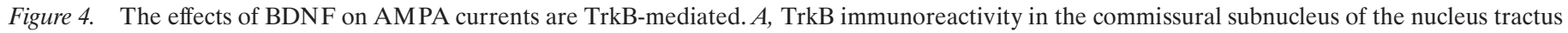

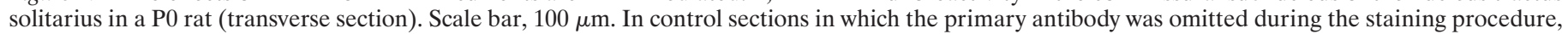

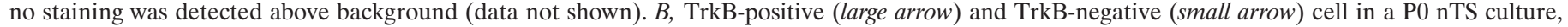

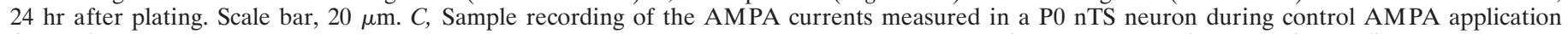

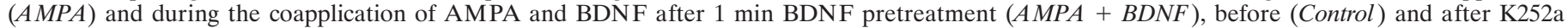

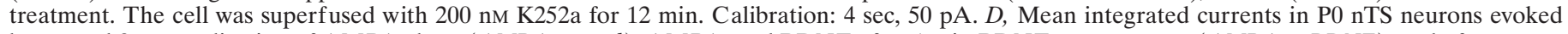

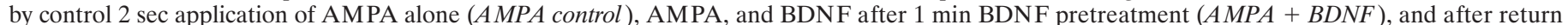

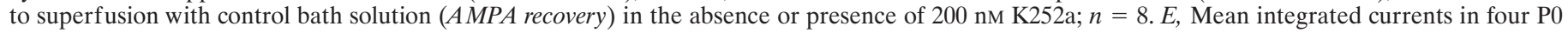

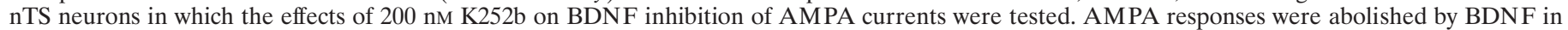
all neurons tested before and after K252b treatment.

it likely that BDNF inhibition of AMPA responses is a general phenomenon and not restricted to sensory relay cells in nTS.

Several lines of evidence indicate that BDNF inhibition of AMPA responses is mediated by activation of TrkB receptors. First, BDNF action was mimicked, in the same cells, by NT-4, also a TrkB ligand, but not by NGF, which acts through TrkA (Chao, 1992; Barbacid, 1994). Second, the effect of BDNF was blocked by K252a, a Trk receptor tyrosine kinase inhibitor (Berg et al., 1992; Nye et al., 1992), but not by the relatively inactive isoform K252b (Kang and Schuman, 1995b; Ross et al., 1995). These findings argue strongly against other potential mechanisms, such as competitive inhibition between BDNF and AMPA at the AMPA-binding site. Moreover, we observed a close correlation between the percentage of nTS neurons in which BDNF inhibited AMPA currents and the percentage of neurons exhibiting TrkB immunoreactivity in culture.

Kafitz and colleagues (1999) recently described a rapid activation of sodium currents by BDNF that is also TrkB-mediated and blocked by $\mathrm{K} 252 \mathrm{a}$. These authors postulate that the rapidity of this response and its sensitivity to tyrosine kinase inhibition may reflect a direct interaction between sodium channels and a pool of already phosphorylated TrkB receptors, a pool that would turn over during the period of pretreatment with K252a. We speculate that a similar mechanism, in which phosphorylated TrkB receptors interact directly with AMPA receptors, may underlie the rapid inhibition of AMPA currents by BDNF described here.

Neuronal activity can regulate the accumulation of AMPA receptors at synapses by rapid membrane trafficking (Lissin et al., 1999) and by regulating the turnover of postsynaptic AMPA receptors (O'Brien et al., 1998), leading to changes in EPSC amplitude. Lissin et al. (1999) demonstrated that the number of AMPA receptor GluR1 subunits can be regulated very rapidly by membrane trafficking and, within minutes, lead to pronounced changes in synaptic efficacy. Therefore, one possible mechanism underlying acute inhibition of AMPA currents by BDNF is a rapid change in the number of available AMPA receptors. Alternatively, TrkB activation could lead to a change in AMPA receptor function without altering receptor availability. BDNF has been shown to rapidly increase phosphorylation of the postsynaptic NMDA receptor subunits 1 and $2 \mathrm{~B}$ in hippocampal and 

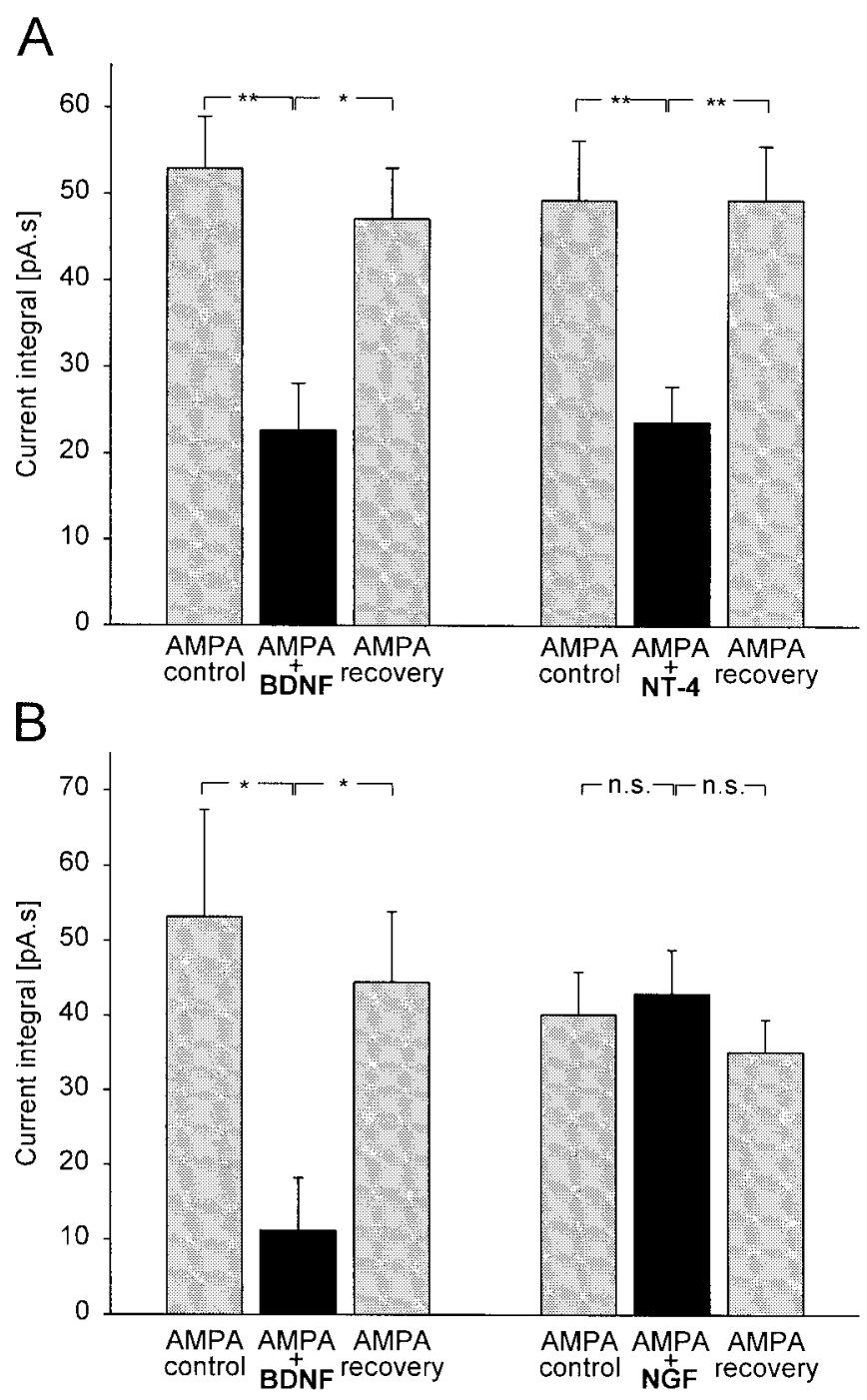

Figure 5. The effects of BDNF, NT-4, and NGF on AMPA currents measured in $\mathrm{P} 0$ nTS neurons. $A, B$, The response to AMPA + BDNF was determined first, as described in Figure 1. After recovery of control AMPA responses, the response to AMPA $+50 \mathrm{ng} / \mathrm{ml} \mathrm{NT}-4(A)$ or 50 $\mathrm{ng} / \mathrm{ml} \mathrm{NGF}(B)$ was determined using the same protocol. $A, n=22 ;{ }^{*} p<$ $0.05 ;{ }^{*} p<0.01 ; B, n=12 ;{ }^{*} p<0.05$; n.s., not significant.

cortical neurons (Suen et al., 1997; Lin et al., 1998). In fact, activity of AMPA receptors has also been shown to be modulated by phosphorylation (Barria et al., 1997; Hayashi et al., 1997; Mammen et al., 1997; Carroll et al., 1998; Carvalho et al., 1999), however, a role for BDNF in this process has not yet been demonstrated.

Our current findings may be of a particular significance in view of recent studies on activity-dependent homeostatic regulation of AMPA receptor-mediated synaptic currents. Turrigiano et al. (1998) have demonstrated a form of synaptic plasticity, termed "synaptic scaling", that changes, in an activity-dependent manner, the strength of synaptic inputs in cortical neuron cultures. Specifically, chronic activity blockade increased, whereas blockade of inhibitory transmission decreased, the amplitude of miniature EPSCs (Turrigiano et al., 1998). In cortical neurons, synaptic scaling is mediated through the activity-dependent release of BDNF (Rutherford et al., 1998), and BDNF has been shown to have opposite effects on the amplitude of AMPA currents in two classes of cortical synapses. Specifically, although chronic exposure to BDNF decreases AMPA currents in pyramidal cells, it increases them in interneurons (Rutherford et al., 1998). Recently, Liao et al. (1999) demonstrated that AMPA receptor blockade also increases the number and size of AMPA receptor clusters in cultured hippocampal neurons and rapidly induces the appearance of AMPA receptors at "silent" synapses. This result suggests that BDNF inhibition of AMPA responses in newborn nTS neurons could ultimately lead to an increase in functional expression of AMPA receptors and an increase in postsynaptic AMPA responses. Indeed, nTS neurons are functionally immature at birth and undergo marked changes in synaptic contacts (Miller et al., 1983), dendritic growth, and electrophysiological properties (Kalia et al., 1993; Denavit-Saubié et al., 1994) during the early postnatal period. Thus, BDNF may play a developmental role in regulating excitability of second-order sensory relay cells in nTS. This could explain why genetic loss of BDNF results in a depression of motor output from the brainstem respiratory rhythm generator (Balkowiec and Katz, 1998), a network that is driven in part by excitatory inputs from nTS interneurons (Bianchi et al., 1995). It is also possible that BDNF plays an acute role in synaptic signaling by restricting the total EPSC. In fact, lowfrequency stimulation of primary afferent inputs to nTS has been shown to inactivate AMPA receptors on second-order relay neurons and depress synaptic strength by a highly robust, $\mathrm{Ca}^{2+}$ independent mechanism (Zhou et al., 1997). Based on our findings, we think it plausible that BDNF, released from primary afferent terminals, could mediate this kind of synaptic modulation. Restriction of total excitatory current might also protect nTS neurons against massive activation of glutamate receptors at high rates of stimulation and potential excitotoxicity (Choi, 1992). BDNF has, for example, been shown to protect cerebellar granule (Lindholm et al., 1993) and cortical (Shimohama et al., 1993) neurons against glutamate-induced neurotoxicity. In distinguishing among these possibilities, it will be important to determine the conditions under which BDNF is released from primary afferent terminals in nTS and whether primary afferents are the only source of BDNF inputs to second-order relay cells.

In summary, our findings demonstrate a novel function for BDNF in acute modulation of AMPA responses in developing sensory relay neurons. These data, combined with the fact that many primary afferents express BDNF, indicate that BDNF could play an important role in regulating excitatory transmission at primary afferent synapses.

\section{REFERENCES}

Ambalavanar R, Ludlow CL, Wenthold RJ, Tanaka Y, Damirjian M, Petralia RS (1998) Glutamate receptor subunits in the nucleus of the tractus solitarius and other regions of the medulla oblongata in the cat. J Comp Neurol 402:75-92.

Andresen MC, Yang M (1990) Non-NMDA receptors mediate sensory afferent synaptic transmission in medial nucleus tractus solitarius. Am J Physiol 259:H1307-H1311.

Apfel SC, Wright DE, Wiideman AM, Dormia C, Snider WD, Kessler JA (1996) Nerve growth factor regulates the expression of brain-derived neurotrophic factor mRNA in the peripheral nervous system. Mol Cell Neurosci 7:134-142.

Balkowiec A, Katz DM (1998) Brain-derived neurotrophic factor is required for normal development of the central respiratory rhythm in mice. J Physiol (Lond) 510:527-533.

Barbacid M (1994) The Trk family of neurotrophin receptors. J Neurobiol 25:1386-1403.

Barria A, Muller D, Derkach V, Griffith LC, Soderling TR (1997) Regulatory phosphorylation of AMPA-type glutamate receptors by CaMKII during long-term potentiation. Science 276:2042-2045. 
Berg MM, Sternberg DW, Parada LF, Chao MV (1992) K-252a inhibits nerve growth factor-induced trk proto-oncogene tyrosine phosphorylation and kinase activity. J Biol Chem 267:13-16.

Bianchi AL, Denavit-Saubié M, Champagnat J (1995) Central control of breathing in mammals: neuronal circuitry, membrane properties, and neurotransmitters. Physiol Rev 75:1-45.

Botsford SA, Dean C, Hopp FA, Seagard JL (1999) Presence of glutamate receptor subtypes on barosensitive neurons in the nucleus tractus solitarius of the dog. Neurosci Lett 261:113-117.

Bozzi Y, Pizzorusso T, Cremisi F, Rossi FM, Barsacchi G, Maffei L (1995) Monocular deprivation decreases the expression of messenger RNA for brain-derived neurotrophic factor in the rat visual cortex. Neuroscience 69:1133-1144.

Brady R, Zaidi SIA, Mayer C, Katz DM (1999) BDNF is a targetderived survival factor for arterial baroreceptor and chemoafferent primary sensory neurons. J Neurosci 19:2131-2142.

Carroll RC, Nicoll RA, Malenka RC (1998) Effects of PKA and PKC on miniature excitatory postsynaptic currents in CA1 pyramidal cells. J Neurophysiol 80:2797-2800.

Carvalho AL, Kameyama K, Huganir RL (1999) Characterization of phosphorylation sites on the glutamate receptor 4 subunit of the AMPA receptors. J Neurosci 19:4748-4754.

Castrén E, Zafra F, Thoenen H, Lindholm D (1992) Light regulates expression of brain-derived neurotrophic factor mRNA in rat visual cortex. Proc Natl Acad Sci USA 89:9444-9448.

Chao MV (1992) Neurotrophin receptors: a window into neuronal differentiation. Neuron 9:583-593.

Choi DW (1992) Excitotoxic cell death. J Neurobiol 23:1261-1276.

Denavit-Saubié M, Kalia M, Pierrefiche O, Schweitzer P, Foutz AS, Champagnat J (1994) Maturation of brain stem neurons involved in respiratory rhythmogenesis: biochemical, bioelectrical and morphological properties. Biol Neonate 65:171-175.

Drewe JA, Childs GV, Kunze DL (1988) Synaptic transmission between dissociated adult mammalian neurons and attached synaptic boutons. Science 241:1810-1813.

Figurov A, Pozzo-Miller LD, Olafsson P, Wang T, Lu B (1996) Regulation of synaptic responses to high-frequency stimulation and LTP by neurotrophins in the hippocampus. Nature 381:706-709.

Fritzsch B, Pirvola U, Ylikoski J (1999) Making and breaking the innervation of the ear: neurotrophic support during ear development and its clinical implications. Cell Tissue Res 295:369-382.

Gonzalez M, Collins WF (1997) Modulation of motoneuron excitability by brain-derived neurotrophic factor. J Neurophysiol 77:502-506.

Hallbook F, Fritzsch B (1997) Distribution of BDNF and trkB mRNA in the otic region of 3.5 and 4.5 day chick embryos as revealed with a combination of in situ hybridization and tract tracing. Int J Dev Biol 41:725-732.

Hamill OP, Marty A, Neher E, Sakmann B, Sigworth FJ (1981) Improved patch-clamp techniques for high-resolution current recording from cells and cell-free membrane patches. Pflügers Arch 391:85-100.

Hayashi Y, Ishida A, Katagiri H, Mishina M, Fujisawa H, Manabe T, Takahashi T (1997) Calcium- and calmodulin-dependent phosphorylation of AMPA type glutamate receptor subunits by endogenous protein kinases in the post-synaptic density. Brain Res Mol Brain Res 46:338-342.

Ip NY, Ibanez CF, Nye SH, McClain J, Jones PF, Gies DR, Belluscio L, Le Beau MM, Espinosa R, Squinto SP, Persson H, Yancopoulos GD (1992) Mammalian neurotrophin-4: structure, chromosomal localization, tissue distribution, and receptor specificity. Proc Natl Acad Sci USA 89:3060-3064.

Kafitz KW, Rose CR, Thoenen H, Konnerth A (1999) Neurotrophinevoked rapid excitation through TrkB receptors. Nature 401:918-921.

Kalia M, Schweitzer P, Champagnat J, Denavit-Saubié M (1993) Two distinct phases characterize maturation of neurons in the nucleus of the tractus solarius during early development: morphological and electrophysiological evidence. J Comp Neurol 327:37-47.

Kang H, Schuman EM (1995a) Long-lasting neurotrophin-induced enhancement of synaptic transmission in the adult hippocampus. Science 267:1658-1662.

Kang HJ, Schuman EM (1995b) Neurotrophin-induced modulation of synaptic transmission in the adult hippocampus. J Physiol (Paris) 89:11-22.

Kerr BJ, Bradbury EJ, Bennett DLH, Trivedi PM, Dassan P, French J, Shelton DB, McMahon SB, Thompson SWN (1999) Brain-derived neurotrophic factor modulates nociceptive sensory inputs and NMDAevoked responses in the rat spinal cord. J Neurosci 19:5138-5148.

Klein R, Lamballe F, Bryant S, Barbacid M (1992) The trkB tyrosine protein kinase is a receptor for neurotrophin-4. Neuron 8:947-956.

Korte M, Carroll P, Wolf E, Brem G, Thoenen H, Bonhoeffer T (1995) Hippocampal long-term potentiation is impaired in mice lacking brainderived neurotrophic factor. Proc Natl Acad Sci USA 92:8856-8860.

Lessmann V, Heumann R (1998) Modulation of unitary glutamatergic synapses by neurotrophin-4/5 or brain-derived neurotrophic factor in hippocampal microcultures: presynaptic enhancement depends on preestablished paired-pulse facilitation. Neuroscience 86:399-413.

Lessmann V, Gottmann K, Heumann R (1994) BDNF and NT-4/5 enhance glutamatergic synaptic transmission in cultured hippocampal neurones. NeuroReport 6:21-25.

Levine ES, Dreyfus CF, Black IB, Plummer MR (1995) Brain-derived neurotrophic factor rapidly enhances synaptic transmission in hippocampal neurons via postsynaptic tyrosine kinase receptors. Proc Natl Acad Sci USA 92:8074-8077.

Levine ES, Dreyfus CF, Black IB, Plummer MR (1996) Selective role for trkB neurotrophin receptors in rapid modulation of hippocampal synaptic transmission. Brain Res Mol Brain Res 38:300-303.

Levine ES, Crozier RA, Black IB, Plummer MR (1998) Brain-derived neurotrophic factor modulates hippocampal synaptic transmission by increasing $N$-methyl-D-aspartic acid receptor activity. Proc Natl Acad Sci USA 95:10235-10239.

Liao D, Zhang X, O'Brien R, Ehlers MD, Huganir RL (1999) Regulation of morphological postsynaptic silent synapses in developing hippocampal neurons. Nat Neurosci 2:37-43.

Lin S-Y, Wu K, Levine ES, Mount HTJ, Suen P-C, Black IB (1998) BDNF acutely increases tyrosine phosphorylation of the NMDA receptor subunit 2B in cortical and hippocampal postsynaptic densities. Brain Res Mol Brain Res 55:20-27.

Lindholm D, Dechant G, Heisenberg C-P, Thoenen H (1993) Brainderived neurotrophic factor is a survival factor for cultured rat cerebellar granule neurons and protects them against glutamate-induced neurotoxicity. Eur J Neurosci 5:1455-1464.

Lissin DV, Carroll RC, Nicoll RA, Malenka RC, von Zastrow M (1999) Rapid, activation-induced redistribution of ionotropic glutamate receptors in cultured hippocampal neurons. J Neurosci 19:1263-1272.

Lohof AM, Ip NY, Poo M-M (1993) Potentiation of developing neuromuscular synapses by the neurotrophins NT-3 and BDNF. Nature 363:350-353.

Mammen AL, Kameyama K, Roche KW, Huganir RL (1997) Phosphorylation of the $\alpha$-amino-3-hydroxy-5-methylisoxazole4-propionic acid receptor GluR1 subunit by calcium/calmodulin-dependent kinase II. J Biol Chem 272:32528-32533.

McAllister AK, Katz LC, Lo DC (1997) Opposing roles for endogenous BDNF and NT-3 in regulating cortical dendritic growth. Neuron 18:767-778

Mendelowitz D, Yang M, Andresen MC, Kunze DL (1992) Localization and retention in vitro of fluorescently labeled aortic baroreceptor terminals on neurons from the nucleus tractus solitarius. Brain Res 581:339-343.

Michael GJ, Averill S, Nitkunan A, Rattray M, Bennett DL, Yan Q, Priestley JV (1997) Nerve growth factor treatment increases brainderived neurotrophic factor selectively in TrkA-expressing dorsal root ganglion cells and in their central terminations within the spinal cord. J Neurosci 17:8476-8490.

Miller AJ, McKoon M, Pinneau M, Silverstein R (1983) Postnatal synaptic development of the nucleus tractus solitarius (NTS) of the rat. Brain Res Dev Brain Res 8:205-213.

Murase K, Ryu PD, Randic M (1989) Excitatory and inhibitory amino acids and peptide-induced responses in acutely isolated rat spinal dorsal horn neurons. Neurosci Lett 103:56-63.

Nye SH, Squinto SP, Glass DJ, Stitt TN, Hantzopoulos P, Macchi MJ, Lindsay NS, Ip NY, Yancopoulos GD (1992) K-252a and staurosporine selectively block autophosphorylation of neurotrophin receptors and neurotrophin-mediated responses. Mol Biol Cell 3:677-686.

O’Brien RJ, Kamboj S, Ehlers MD, Rosen KR, Fischbach GD, Huganir RL (1998) Activity-dependent modulation of synaptic AMPA receptor accumulation. Neuron 21:1067-1078.

Ozawa S, Kamiya H, Tsuzuki K (1998) Glutamate receptors in the mammalian central nervous system. Prog Neurobiol 54:581-618.

Patterson SL, Abel T, Deuel TAS, Martin KC, Rose JC, Kandel ER (1996) Recombinant BDNF rescues deficits in basal synaptic transmis- 
sion and hippocampal LTP in BDNF knockout mice. Neuron 16:1137-1145.

Rae J, Cooper K, Gates P, Watsky M (1991) Low access resistance perforated patch recordings using amphotericin B. J Neurosci Methods 37:15-26.

Ross AH, McKinnon CA, Daou M-C, Ratliff K, Wolf DE (1995) Differential biological effects of K252 kinase inhibitors are related to membrane solubility but not to permeability. J Neurochem 65:2748-2756.

Rutherford LC, DeWan A, Lauer HM, Turrigiano GG (1997) Brainderived neurotrophic factor mediates the activity-dependent regulation of inhibition in neocortical cultures. J Neurosci 17:4527-4535.

Rutherford LC, Nelson SB, Turrigiano GG (1998) BDNF has opposite effects on the quantal amplitude of pyramidal neuron and interneuron excitatory synapses. Neuron 21:521-530.

Scharfman HE (1997) Hyperexcitability in combined entorhinal/hippocampal slices of adult rat after exposure to brain-derived neurotrophic factor. J Neurophysiol 78:1082-1095.

Schecterson LC, Bothwell M (1992) Novel roles for neurotrophins are suggested by BDNF and NT-3 mRNA expression in developing neurons. Neuron 9:449-463.

Shimohama S, Tamura Y, Akaike A, Tsukahara T, Ohara O, Watanabe S, Kimura J (1993) Brain-derived neurotrophic factor pretreatment exerts a partially protective effect against glutamate-induced neurotoxicity in cultured rat cortical neurons. Neurosci Lett 164:55-58.

Smith BN, Dou P, Barber WD, Dudek FE (1998) Vagally evoked synaptic currents in the immature rat nucleus tractus solitarii in an intact in vitro preparation. J Physiol (Lond) 512:149-162.

Song D-K, Choe B, Bae JH, Park WK, Han IS, Ho W-K, Earm YE (1998) Brain-derived neurotrophic factor rapidly potentiates synaptic transmission through NMDA, but suppresses it through non-NMDA receptors in rat hippocampal neuron. Brain Res 799:176-179.
Suen P-C, Wu K, Levine ES, Mount HTJ, Xu J-L, Lin S-Y, Black IB (1997) Brain-derived neurotrophic factor rapidly enhances phosphorylation of the postsynaptic $N$-methyl-D-aspartate receptor subunit 1 . Proc Natl Acad Sci USA 94:8191-8195.

Thoenen H (1995) Neurotrophins and neuronal plasticity. Science 270:593-598.

Tonra JR (1999) Classical and novel directions in neurotrophin transport and research: anterograde transport of brain-derived neurotrophic factor by sensory neurons. Microsc Res Tech 45:225-232.

Turrigiano GG, Leslie KR, Desai NS, Rutherford LC, Nelson SB (1998) Activity-dependent scaling of quantal amplitude in neocortical neurons. Nature 391:892-896.

Wetmore C, Olson L (1995) Neuronal and nonneuronal expression of neurotrophins and their receptors in sensory and sympathetic ganglia suggest new intercellular trophic interactions. J Comp Neurol 353:143-159.

Yan Q, Radeke MJ, Matheson CR, Talvenheimo J, Welcher AA, Feinstein SC (1997) Immunocytochemical localization of TrkB in the central nervous system of the adult rat. J Comp Neurol 378:135-157.

Zhang J, Mifflin SW (1998) Differential roles for NMDA and nonNMDA receptor subtypes in baroreceptor afferent integration in the nucleus of the solitary tract of the rat. J Physiol (Lond) 511:733-745.

Zhou X-F, Chie ET, Rush RA (1998) Distribution of brain-derived neurotrophic factor in cranial and spinal ganglia. Exp Neurol 149:237-242.

Zhou X-F, Rush RA (1996) Endogenous brain-derived neurotrophic factor is anterogradely transported in primary sensory neurons. Neuroscience 74:945-951.

Zhou Z, Champagnat J, Poon C-S (1997) Phasic and long-term depression in brainstem nucleus tractus solitarius neurons: differing roles of AMPA receptor desensitization. J Neurosci 17:5349-5356. 